\title{
Climate Change Carbon losses in the Alps
}

Soil carbon stocks depend on inputs from decomposing vegetation and returns to the atmosphere as $\mathrm{CO}_{2}$. Monitoring of carbon stocks in German alpine soils has shown large losses linked to climate change and a possible positive feedback loop.

\section{Guy Kirk}

The response of the terrestrial carbon cycle to global change is one of the main uncertainties in current climate change predictions ${ }^{1}$. Most terrestrial carbon is held in soils as organic matter derived from the decay of plants. Soil organic matter accounts for roughly three times more carbon than living vegetation, and for more carbon than vegetation and the atmosphere combined. Because elevated atmospheric $\mathrm{CO}_{2}$ concentrations have a fertilizing effect on plant growth, anthropogenic $\mathrm{CO}_{2}$ emissions have triggered increases in the land carbon $\operatorname{sink}^{2}$. However, models predict that other factors - such as water and nutrients - will eventually become limiting to plant growth, and hence to the land carbon sink. In contrast, the turnover of soil organic matter producing $\mathrm{CO}_{2}$ is expected to increase as the Earth warms. As a result, simulations using coupled carbon-climate models predict that the land surface will become a net source of $\mathrm{CO}_{2}$ before the end of the century, leading to a feedback loop between climate and soil carbon losses: increased emissions of $\mathrm{CO}_{2}$ from soil organic matter will lead to enhanced warming, which may then feedback to further soil organic matter losses. Prietzel and colleagues ${ }^{3}$, writing in Nature Geoscience, provide evidence that warming has already caused a decline in soil organic matter in the German Alps.

The umbrella term "soil carbon" covers a diverse array of molecules, which are stabilised to varying extents by binding to soil minerals and by physical protection within soil aggregates ${ }^{4}$. Its turnover is mediated by soil microbes, with half-times ranging from weeks to millennia. Physical protection within aggregates can render soil carbon inaccessible to microbes and the enzymes they produce to cleave complex carbon molecules into easily digestible compounds. Like other metabolic and enzymatic processes, rates of turnover are sensitive to temperature and moisture. Increasing temperatures associated with climate change are expected to increase soil carbon turnover rates ${ }^{1}$, but direct evidence that this is currently taking place is limited. Since high elevation ecosystems are expected to warm more quickly than other parts of the planet, with associated changes in snow cover and freeze-thaw cycles, they are a good place to determine whether warming is already causing soil carbon losses.

Prietzel and colleagues ${ }^{3}$ measured losses of carbon from forest soils in the German Alps over the past 30 years, which they link to higher summer temperatures. They did this with repeated sampling of soils at 35 sites across both forests and pastures. They found no change in soil carbon in the pasture areas, but large losses in absolute and percentage terms in soils with high carbon stocks in lower elevation forests $(<1100 \mathrm{~m})$. Changes in management weren't responsible for the carbon losses, because forests across the German Alps have been under constant, low intensity management for more than 50 years. Instead, the losses matched changes in mean summer temperatures at the low elevation sites: temperatures at these elevations increased by $0.5{ }^{\circ} \mathrm{C}$ per decade over the survey period, even though mean winter temperatures at these elevations decreased by $0.3{ }^{\circ} \mathrm{C}$ per decade.

Measuring climate-induced changes in soil carbon is difficult. Measurable changes occur on decadal time scales, and it can be challenging to detect the changes against large background concentrations and the tremendous spatial variability inherent in soils. Further, the effects of climate must be disentangled from the effects of past changes in land use or management, which may persist for many decades. It is therefore crucial to have long-term soil monitoring schemes that are properly designed, managed and resourced to account for these factors, such as the scheme used by Prietzel et al.

Various repeated soil inventories have been made in different parts of the world over the past two or three decades, and some have shown losses of carbon but others gains. In most cases the changes 
could be attributed to changes in land use and management. For example, large losses of carbon from soils across England and Wales during the 1980s and $90 \mathrm{~s}^{5}$ were largely due to land use changes, but up to $10 \%$ could have been due to climate change ${ }^{6}$. The losses of the order of $100 \mathrm{~g} \mathrm{C} \mathrm{m}^{-2} \mathrm{yr}^{-1}$ reported by Prietzel and colleagues are somewhat greater than those found in England and Wales ${ }^{5}$ for forest soils with similar carbon contents but at mostly lower elevations.

To understand how the sources and sinks of greenhouse gases will change with the climate, it is essential to have reliable mathematical models. But simulating soil carbon processes is a particularly thorny challenge. In addition to the inherent complexity of soil carbon and its interactions with soil physical and chemical conditions, a number of other factors complicate the picture. The availability of readily decomposed substrates, such as root secretions, may fuel the turnover of otherwise morestable components in so-called priming effects. Soil microbes may adapt to warmer temperatures, and thereby reduce or in some cases increase the magnitude of soil carbon responses to climate change ${ }^{7}$. Further, the carbon cycle is inextricably linked to other nutrient cycles, and changes in these other cycles, such as changes in atmospheric nitrogen deposition, can have cascading effects on plant productivity and soil carbon dynamics ${ }^{8}$. Lastly, extreme weather events, such as drought or storms, can alter the turnover rates of terrestrial carbon pools leading to prolonged release of $\mathrm{CO}_{2}$ to the atmosphere? .

Models must be under-pinned by field studies, and ultimately by long-term soil monitoring at regional and national scales, of which the study by Prietzel and colleagues ${ }^{3}$ is exemplary. Their evidence that climate change has already started depleting soil carbon in the German Alps raises the possibility that a positive feedback between climate and ecosystems is beginning. Combined with the expected decline in the fertilization effect from elevated atmospheric $\mathrm{CO}_{2}$ concentrations, soils could become important contributors to accelerating climate change.

Guy Kirk is in the School of Water, Energy and Environment, Cranfield University, Cranfield, Bedford MK43 OAL, UK.

e-mailg.kirk@cranfield.ac.uk

\section{References}

1. Ciais, P., et al. in Climate Change 2013: The Physical Science Basis (ed. Stocker, T. F. et al.) 465-570 (Cambridge Univ. Press, 2013).

2. Zhu, Z., et al. Nature Clim. Change doi:10.1038/nclimate3004 (2016).

3. Prietzel, J., Zimmermann, L., Schubert, A. \& Christophel, D. Nature Geosci. ... (2016)

4. Schmidt, M. W. et al. Nature 478, 49-56 (2011)

5. Bellamy, P. H., Loveland, P. J., Bradley, R. I., Lark, R. M. \& Kirk, G. J. D. Nature 437, 245-248 (2005).

6. Kirk, G. J. D. \& Bellamy, P. H. Eur. J. Soil Sci. 61, 406-411 (2010).

7. Karhu, K. et al. Nature 513, 81-84 (2014).

8. Fernandez-Martinez, M. et al. Nature Clim. Change 4, 471-476 (2014).

9. Reichstein, M. et al. Nature 500, 287-295 (2013). 


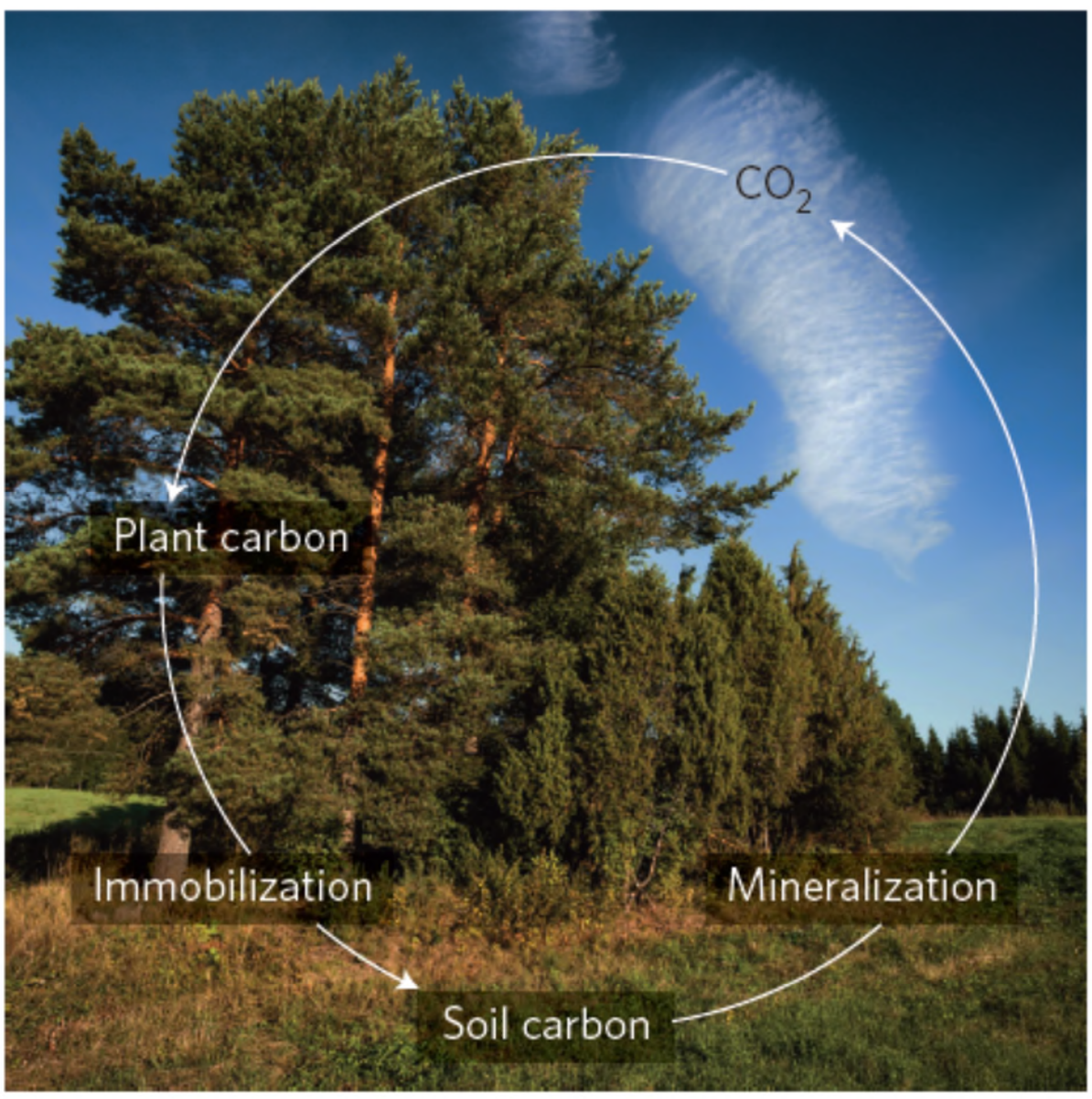

Figure 1 | Soil carbon dynamics. Plant productivity — and plant carbon stocks - can be stimulated by increased atmospheric $\mathrm{CO}_{2}$ concentrations. That plant carbon is then decomposed and converted to soil carbon, where it can remain immobilized for weeks to thousands of years before being mineralized to $\mathrm{CO}_{2}$ and released back to the atmosphere. However, warming can stimulate the decomposition and mineralization of soil carbon, leading to increased emissions of $\mathrm{CO}_{2}$ to the atmosphere. Prietzel et al. ${ }^{3}$ used repeated soil measurements in the German Alps over the last 30 years to show that soil carbon has decreased in managed forests concomitantly with an increase in temperatures. 